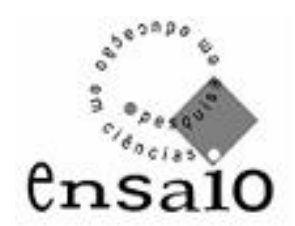

Vol. 10 no. 1 jun. 2008

\title{
Formação acadêmica em serviço: avanços, resistências e contradições de um grupo de professores de ciências ${ }^{1}$
}

\author{
Education in service: advances, resistance and contradictions of a group of \\ teachers of science
}

Daisi Teresinha Chapani²

\begin{abstract}
Resumo
Com o propósito de colaborar no entendimento das relações estabelecidas entre a prática docente e os conhecimentos constituídos em processo de formação acadêmica em serviço, foi realizada, entre 2004 e 2006, uma pesquisa com um grupo de docentes participante de um curso de Licenciatura em Ciências Biológicas. Os dados foram obtidos por meio de questionários, entrevistas e observações. Os resultados revelaram que o processo formativo teve grande impacto sobre seus freqüentadores. Tomando-se como referência os fundamentos teórico-metodológicos presentes no projeto do curso, notou-se que o grupo apresentou avanços, resistências e contradições e que a pretensão de formar professores reflexivos não foi plenamente alcançada visto que, em muitos aspectos, os docentes continuaram dependentes de uma fonte externa capaz de lhes oferecer conhecimentos prontos.
\end{abstract}

Palavras-chave: formação docente, formação em serviço, professor reflexivo.

\begin{abstract}
This paper aimed at discussing connection between pedagogical practice and the knowledge constructed on in-service formation. For this, we was carried, since 2004 until 2006, a research with a group of sciences and biological sciences teachers. Data was obtained from questionnaires, interviews and observation. The results revealed that this formative process had great impact on these teachers. We noticed that the group presented advances, returns and contradictions and that after course, the teachers didn't see themselves like knowledge producing
\end{abstract}

Keywords: in-service education; teacher education; reflective practitioner.

\footnotetext{
${ }^{1}$ Apoio: FAPESB

${ }^{1}$ Departamento de Ciências Biológicas da UESB-Jequié e doutoranda do programa de pós-graduação

“Educação para a Ciência” da UNESP-Bauru “Educação para a Ciência” da UNESP-Bauru
} 


\section{1 - Introdução}

Vol. 10 no. 1 jun. 2008

Com a aprovação da lei 9.394/96, que explicitou em seu artigo 62 (regulamentado pelo decreto 3.276/1999) e no parágrafo 4 do artigo $87^{2}$ a necessidade de formação superior para docentes de escola básica, houve uma corrida para a graduação daqueles que não dispunham dessa formação, mas que, no entanto, já atuavam no magistério.

Devido ao grande número de professores em atuação sem a formação mínima exigida $^{3}$, a Secretaria de Educação da Bahia implantou, a partir de 2003, três programas de formação docente: modalidade presencial, destinado a formar em serviço professores em licenciatura plena para atuação nas últimas séries do ensino fundamental e para o ensino médio; modalidade à distância, visando oferecer complementação pedagógica a fim de licenciar bacharéis e Proformar com o propósito de oferecer curso normal em serviço para professores das primeiras séries do ensino fundamental (BAHIA, 2006). A modalidade presencial foi regulamentada pelo Decreto 8.523/03 e sua efetivação ocorreu por meio de convênios celebrados entre a Secretaria de Educação e as universidades públicas.

Em 2003, foi criado no Campus de Jequié da Universidade Estadual do Sudoeste da Bahia (UESB), o Curso de Licenciatura em Ciências Biológicas: modalidade presencial, cuja intenção era “formar em nível superior aqueles docentes que atuam nas disciplinas da área de ciências e biologia, e que ainda não tiveram a oportunidade para freqüentar um curso deste nível, atendendo à importante demanda social no sentido de capacitar esses docentes e contribuir para a melhoria do ensino público nesta região, sobretudo na área da educação científica.” (UESB, 2003, p.3).

Trata-se de uma modalidade formativa que, a rigor, não se constitui em formação inicial nem continuada, e que será denominada, neste trabalho, de formação acadêmica em serviço. Temos conhecimento de poucos estudos sobre cursos dessa

\footnotetext{
2 Art. 62: “a formação de docentes para atuar na educação básica far-se-á em nível superior, em curso de licenciatura, de graduação plena, em universidades e institutos superiores de educação, admitida, como formação mínima para o exercício do magistério na educação infantil e nas quatro primeiras séries do ensino fundamental, a oferecida em nível médio, na modalidade Normal.” Parágrafo $4^{\circ}$ do artigo 87: "é instituída a Década da Educação, a iniciar-se um ano a partir da publicação desta Lei. § $4^{\circ}$ Até o fim da Década da Educação somente serão admitidos professores habilitados em nível superior ou formados por treinamento em serviço.”

${ }^{3}$ Em 2004, apenas aproximadamente 36\% dos docentes das séries finais do ensino fundamental e 60\% dos que lecionavam no ensino médio possuíam formação em nível superior (BAHIA, 2005).
} 


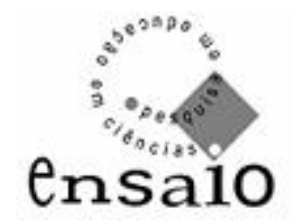

Vol. 10 no. 1 jun. 2008

natureza, especialmente os presenciais e que buscam formar docentes para as séries finais do ensino fundamental e para o ensino médio. Santos (2003), analisando um curso de Pedagogia ocorrido na região do Bico do Papagaio, no estado de Tocantins, ofertado para os professores da rede estadual, considerou como aspectos positivos o respeito aos saberes dos alunos e a preocupação em construir a dimensão de pesquisa, porém reputou o processo formativo como aligeirado e qualificou de preocupante o fato de não terem sido oferecidas licenciaturas específicas por área do saber. Reis (2007), ao realizar um estudo sobre um curso de Licenciatura em Matemática, em uma localidade do interior de Goiás, notou que este contribuiu para que os docentes obtivessem a qualificação profissional exigida pela atual legislação, no entanto, não obteve evidências significativas em relação ao desenvolvimento profissional de seus participantes.

Assim, pretende-se contribuir com a discussão sobre esse tipo de processo formativo, enfocando novos aspectos sobre o assunto. Para tanto, são utilizados dados de uma pesquisa realizada durante a vigência de um curso de Licenciatura em Ciências Biológicas (anos letivos de 2004, 2005 e 2006), a qual visou melhor conhecer as interações entre os saberes constituídos pelos professores no decorrer de sua atuação profissional e os estabelecidos pela participação no curso em questão. Entre os diversos aspectos abordados na referida investigação, este trabalho tratará de possíveis mudanças nas concepções relativas à prática docente aludidas pelo grupo de professores cursistas, tomando-se como referência os pressupostos teóricos que embasaram o projeto do curso.

\section{2 - Procedimentos Metodológicos}

Utilizou-se de uma abordagem qualitativa, caracterizada por se ter feito uso de dados descritivos constituídos no próprio ambiente com o foco mais no processo formativo que em seu produto. Em virtude de ter se consistido no estudo detalhado de um contexto específico e bem delimitado, foi qualificado como um estudo de caso (BOGDAN; BIKLEN, 1994).

Os dados foram constituídos por meio de diferentes instrumentos ao longo dos três anos de curso, com o conhecimento e o consentimento expresso dos informantes ${ }^{4}$.

\footnotetext{
${ }^{4}$ Aos quais somos profundamente gratos.
} 


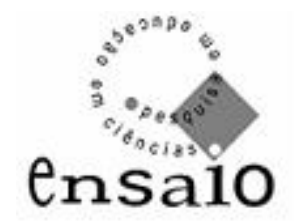

Vol. 10 no. 1 jun. 2008

Para tanto, fez uso de: i) um questionário composto por questões de múltipla escolha, aplicado pela coordenação geral aos cursistas no primeiro semestre; ii) entrevistas de grupo de foco (FLICK, 2004), nas quais os participantes (organizados em dois grupos de 6 e um grupo de 4 professores, e mediados por um professor formador) discutiram suas motivações para ingresso e permanência no curso e as relações que vinham estabelecendo entre esse e sua prática; iii) questionário com uma única questão discursiva, adaptada de Campos e Diniz (2001), aplicado no último semestre; iv) relatório simplificado sobre atividade desenvolvida na disciplina Estágio III; v) observações da prática realizadas pelos formadores a partir do quarto semestre.

Do conjunto de dados obtidos, foram aqui considerados apenas aqueles que estão diretamente relacionados ao objetivo deste trabalho. As falas dos professores, utilizadas para ilustrar e aprofundar as discussões, foram extraídas das entrevistas realizadas no terceiro semestre e do questionário aplicado ao final do curso. Ressaltese que a autora atuou como docente de disciplinas pedagógicas (no primeiro e no último semestres) e como coordenadora do curso (pelo período de um ano, entre 2004 e 2005).

\section{3 - Referenciais teóricos}

Neste tópico discutem-se brevemente os atuais modelos relacionados à formação docente, com particular ênfase ao conceito de professor reflexivo, visto que o curso embasava-se nessa premissa teórica.

\section{1 - Racionalidades que embasam os atuais modelos formativos}

Nos debates sobre os modelos de formação docente, tem-se estabelecido que estes se fundamentam em três tipos de racionalidades: técnica, prática e crítica (DINIZ-PEREIRA, 2002).

Nos modelos baseados na racionalidade técnica, tidos como hegemônicos, os problemas educacionais são considerados de natureza técnica e demandam soluções pautadas em procedimentos racionais, ditados pela ciência. Apresentam como principais características: i) treinamento de habilidades; ii) descontextualização dos conteúdos da realidade profissional; iii) dicotomia entre teoria e prática, sendo a segunda entendia como instância de aplicação da primeira. O professor é colocado em situação de mero executor de recomendações estabelecidas pelos pesquisadores 


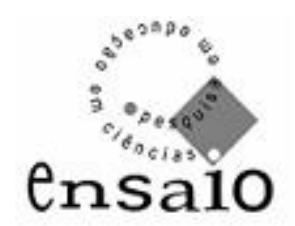

Vol. 10 no. 1 jun. 2008

(MONTEIRO, 2001, DINIZ-PEREIRA, 2002; RAMALHO, NUÑEZ e GAUTHIER, 2004). Apesar das críticas, esse tipo de racionalidade “ainda está presente no imaginário e prática social de muitos educadores” (MONTEIRO, 2001, p. 122).

Os modelos baseados na racionalidade prática, embora apresentados há algumas décadas, ganharam forte notoriedade no Brasil nos últimos anos. Consideram que a prática apresenta um estatuto epistemológico próprio e dão status privilegiado ao saber produzido nesta instância. Buscam superar as deficiências apresentadas pela racionalidade técnica, particularmente a relação linear e mecânica entre o conhecimento técnico-científico e a prática na sala de aula, levando em consideração as características dos fenômenos educativos e colocando o professor no centro desse processo. (SHÖN, 1995; MONTEIRO, 2001; DINIZ-PEREIRA, 2002; PIMENTA, 2005).

Para alguns pesquisadores (CONTRERAS, 2002; DINIZ-PEREIRA, 2002), embora os modelos apresentados anteriormente, apresentem diferenças importantes no que diz respeito à formação docente, comungam, entretanto, de princípios semelhantes no que tange aos propósitos da educação. Neste sentido, indicam modelos baseados na racionalidade crítica como uma alternativa mais radical. Esta abordagem considera o professor como intelectual transformador, já que não se trata apenas de se ter um compromisso com a transmissão de saber crítico, mas com a própria transformação social, por meio da capacitação para pensar e agir criticamente.

\section{2 - A metáfora do professor reflexivo}

O Projeto do Programa de Formação (BAHIA, 2003) assim como o Projeto do Curso (UESB, 2003) fundamentaram-se teórico-metodologicamente em um modelo formativo tributário da racionalidade prática, especialmente no de professor reflexivo.

Desde a década de 1990 a expressão “professor reflexivo” passou a fazer parte dos discursos sobre formação docente no Brasil. Ela originou-se principalmente dos trabalhos de Schön, que propôs uma formação profissional baseada na epistemologia da prática, na qual a construção do conhecimento se dá na reflexão, análise e problematização da prática. (PIMENTA, 2005).

Sustenta-se em dois movimentos: a experiência e a reflexão. Desta forma, diferencia-se o conhecimento-na-ação (tácito, implícito, interiorizado, que não precede a ação, mas está contido nela); reflexão na ação (construção de novos 


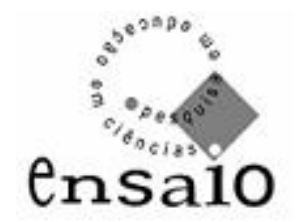

Vol. 10 no. 1 jun. 2008

conhecimentos em situações que fogem da rotina); reflexão sobre a reflexão na ação (momento no qual o professor busca soluções para novos problemas pela análise, contextualização, compreensão de suas origens, apropriação de teorias sobre o problema, enfim, realiza uma investigação) (PIMENTA, 2005).

Shön (1995) difere o saber escolar, isto é, “o tipo de conhecimento que os professores são supostos possuir e transmitir aos alunos” (p. 81) do conhecimento-naação, como já explicitado, aquele que é tácito, espontâneo, intuitivo, experimental, cotidiano. Desta maneira, a formação de professores reflexivos esbarra em dificuldades: a universidade valoriza sobremaneira o conhecimento escolar, ou seja, teórico, em detrimento do conhecimento-na-ação, eminentemente prático, havendo, portanto, a necessidade da produção de um novo currículo condizente com a epistemologia da prática.

Para Ghedin (2005), o conhecimento constitui-se na relação entre a prática e a interpretação da mesma. Assim,

a reflexão sobre a prática constitui o questionamento da prática, e um questionamento efetivo inclui intervenções e mudanças. Para isso há de se ter, antes de tudo, de algum modo, algo que desperte a problematicidade desta situação. A capacidade de questionamento e de autoquestionamento é pressuposto para a reflexão (GHEDIN, 2005 P. 132).

Diversos estudiosos, como Contreras (2002) e Pimenta (2005), destacam as contribuições que essa abordagem trouxe às discussões sobre a formação docente, entre elas o entendimento que a prática profissional pode, por si mesma, constituir-se em um processo de construção do conhecimento, por meio da exploração, do diálogo com a situação e guiada pela reflexão, pois nem sempre se encontra submetida à lógica da aplicação de técnicas e estratégias que se deduzem da pesquisa acadêmica.

No entanto, destacam também seus limites, os quais decorrem tanto da própria teoria quanto das distorções a que ela foi submetida. No primeiro caso, tem-se a constituição de profissionais que se envolvem individualmente no processo reflexivo com o objetivo de modificar, de forma imediata, o que está em suas mãos. Além disso, não indica de que maneira a reflexão, que supostamente incluiria aspectos institucionais, poderia levar a uma rediscussão das concepções básicas de análise e valorização que os profissionais possuem. No segundo caso, registra-se a legitimação 


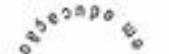 \\ .

Vol. 10 no. 1 jun. 2008

das atuais reformas educacionais, levadas a cabo por políticas neoliberais, e a responsabilização dos docentes pelos problemas estruturais do ensino. (CONTRERAS, 2002; PIMENTA, 2005).

Críticas têm sido feitas às propostas de Schön, especialmente por aqueles que acreditam que a epistemologia que embasa sua teoria desvaloriza o conhecimento científico (DUARTE, 2003). Além disso, também têm sido formuladas restrições quanto ao fato de essas idéias supervalorizarem o professor como indivíduo, ignorando-se o contexto institucional; criarem expectativas de que a reflexão seria suficiente para a solução de todos os problemas da prática; assumirem uma conotação técnica relativa ao treinamento para que o professor torne-se reflexivo, além de, eventualmente, terem se constituído em um modismo aplicado acriticamente (PIMENTA 2005).

Para Pimenta (2005) é justamente a teoria, necessária à reflexão, que possibilita superar o "praticismo" que poderia advir do conceito de professor reflexivo:

O saber docente não é formado apenas pela prática, sendo também nutrido pelas teorias da educação. Dessa forma, a teoria tem importância fundamental na formação dos docentes, pois dota os sujeitos de variados pontos de vista para uma ação contextualizada, oferecendo perspectivas de análise para que os professores compreendam os contextos históricos, sociais, culturais, organizacionais e de si próprios como profissionais (PIMENTA, 2005 p. 24).

\section{4 - O curso de Licenciatura em Ciências Biológicas}

Os participantes do curso de licenciatura plena em Ciências Biológicas eram professores efetivos da rede estadual de ensino que possuíam o nível secundário e voluntariamente apresentaram-se para o processo seletivo. Apresentavam idade acima de 31 anos, tempo médio de magistério de 21 anos, sendo que a maior parte era casada, lecionava em uma única escola e trabalhava 40 horas por semana. Apenas um dos participantes era do sexo masculino.

Em 2004, iniciaram o curso 28 professores, embora três tenham desistido logo no primeiro semestre por não terem conseguido conciliar o horário das aulas com do trabalho, um se afastou das atividades docentes e outro foi desligado do programa por não ter obtido o aproveitamento mínimo exigido. Portanto, concluíram o curso 23 professores, ou seja, $82 \%$ dos matriculados. 


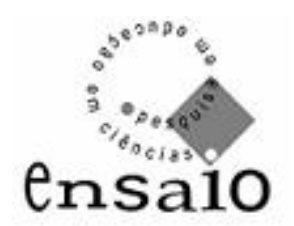

Vol. 10 no. 1 jun. 2008

O curso teve a duração de três anos, tempo mínimo exigido para sua integralização, conforme determina Resolução CNE/CP 2/2002. As disciplinas relacionadas à prática como componente curricular foram distribuídas ao longo do curso, a partir do primeiro semestre. Os conteúdos curriculares de natureza científicocultural abrangeram aqueles clássicos da licenciatura em Biologia. Foram oferecidas atividades acadêmico-científico-culturais, levando-se em consideração as necessidades específicas desse grupo, que também foi estimulado a participar de diversas outras atividades na universidade para a complementação das 200 horas relativas a esse item. Buscando levar à reflexão e a alterações na prática pedagógica, o estágio supervisionado configurou-se em forma de inovações implementadas pelos professores cursistas em suas salas de aula e foi acompanhado, a partir do quarto semestre, por professores formadores da área pedagógica, os quais também orientaram o Trabalho de Conclusão de Curso (TCC), executado em forma de uma pesquisa em ensino de ciências, em estreita relação com a prática docente.

As aulas, presenciais, foram desenvolvidas na universidade, no período letivo regular. A carga horária do curso foi menor que a da licenciatura pré-serviço da mesma instituição, o que foi justificado pelo conhecimento que os participantes já possuíam devido sua experiência. Ressalte-se que, na verdade, o curso organizou-se com 2.600 horas em virtude da possibilidade facultada pelo parágrafo único, do artigo $1^{\circ}$, da Resolução CNE/CP 2/2002, aos alunos que exerçam atividade docente regular na educação básica, reduzir a carga horária do estágio curricular supervisionado em até duzentas horas.

Diversos estudiosos (DINIZ-PEREIRA, 1999; FREITAS, 2003; BRZEZINSKI, 2005; PIMENTA, 2005) já alertavam para a possibilidade de a valorização da prática ser tomada de maneira equivocada levando a uma abreviação da formação docente, visto que o conceito de professor como prático-reflexivo, depurado de sua dimensão político-epistemológica, ter sido apropriado de forma a atender aos propósitos das políticas neoliberais. No presente caso, esse fato justificou um programa formativo de menor carga horária, concretizando o que já admitia DinizPereira (1999, p. 114):

(...) as horas trabalhadas em sala de aula, sem, necessariamente, um planejamento, uma intencionalidade formativa, podem assim, ser contabilizadas nos novos cursos de licenciatura pelos profissionais já em exercício na escola. Como conseqüência, diminui significativamente a 


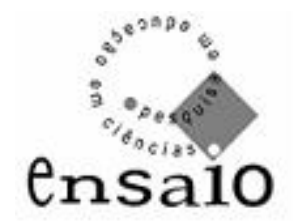

Vol. 10 no. 1 jun. 2008

carga horária dos cursos de formação inicial, o que, obviamente, não é desejável e representa um imenso retrocesso em termos de preparação desses profissionais.

Esse aspecto foi inclusive abordado pelos professores formadores do curso, os quais alegaram que a carga horária reduzida das disciplinas levou-os a promover mudanças em suas práticas, particularmente pelo encurtamento dos conteúdos (SANTOS e CHAPANI; 2006).

No caso estudado, se, em alguns aspectos, o conceito de professor reflexivo foi mal utilizado, visando à abreviação da formação e, em conseqüência, à redução de seus custos, em outros, no entanto, seguiram-se certos preceitos oriundos dessa mesma matriz epistemológica que visaram efetivamente fundamentar a ação docente, como foi o caso da realização de pesquisa pelos licenciandos.

O programa de formação de professores considerava “a pesquisa, com foco na tematização da prática pedagógica dos professores”, como um “princípio formativo da maior relevância” (BAHIA, 2003 p. 17). Desta maneira, o curso pretendia imprimir um caráter de formação pela pesquisa, envolvendo os professores participantes em situações de reflexão e análise da prática docente, o que ocorreu especialmente nas disciplinas relacionadas à prática como componente curricular e foi sistematizado no estágio supervisionado e na elaboração do TCC.

Ressalte-se que o modelo formativo baseado no conceito de professor reflexivo foi tomado como referencial de análise neste trabalho por ter embasado o projeto do curso, não havendo sido verificado, porém, em que medida este modelo foi efetivamente implementado. Santos e Chapani (2006), investigando a atuação dos professores formadores do curso em questão, notaram que, especialmente os das disciplinas de conteúdos específicos de ciências e biologia, nem sempre consideraram a prática dos professores cursistas como elemento central na formulação do currículo.

\section{5 - Movimentos de mudanças e resistências.}

Anteriormente já havia sido notado o forte impacto que o curso teve sobre os participantes (CHAPANI et al. 2006). No campo pessoal, foi sensível o aumento da auto-estima dos docentes; no profissional, relataram maior segurança em sua vida funcional, especialmente em relação à atribuição de aulas, bem como uma atitude 


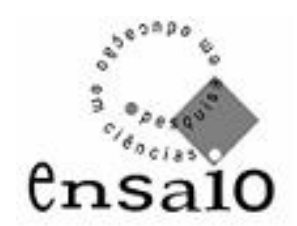

Vol. 10 no. 1 jun. 2008

mais respeitosa por parte de seus alunos, colegas e superiores; no pedagógico, houve aumento da competência disciplinar e da habilidade didática. Tudo isso levou a alterações em suas práticas pedagógicas.

No entanto, em consonância com o encontrado na literatura consultada (MARCELO, 1998; FREITAS E VILLANI, 2002), percebeu-se, também, que o curso não conseguiu proporcionar mudanças profundas nas concepções epistemológicas dos docentes. Freitas e Vilani (2002) já apontavam que uma das características da formação em serviço são as resistências dos professores às mudanças, as quais podem se originar nas teorias implícitas que permeiam sua prática e em seus valores e crenças pessoais. Isso não significa que o processo tenha sido estático, ao contrário, notaramse movimentos que envolveram, segundo os referenciais explicitados no projeto do curso, avanços, resistências e contradições.

Os docentes consultados fizeram diversas referências às dificuldades relacionadas ao magistério (falta de reconhecimento profissional; má remuneração salarial; dificuldades de atualização em serviço e os problemas vivenciados no cotidiano escolar), realçaram o empenho pessoal e o amor à profissão como forma de superação dessas dificuldades e enfatizaram a dimensão afetiva da mesma, como se vê nos seguintes depoimentos; "apesar dela [profissão docente] ser muito difícil e também desvalorizada, desrespeitada, mal remunerada, goste do que você está fazendo, pois o gosto pela profissão supera todos estes obstáculos”; “(...) a vocação, responsabilidade, compromisso e vontade de acertar são fatores importantíssimos para o bom desenvolvimento na educação".

O aspecto individualista da ação docente fica bastante claro no seguinte depoimento:

\begin{abstract}
O professor se depara com a rotina, a falta de interesse dos alunos e o desnível de aprendizado entre eles numa mesma classe, a falta de tempo para uma renovação de técnicas, a desvalorização da profissão e, principalmente, a diferença salarial. Mas acredito que com vontade e predisposição podemos superar esses entraves, indo em busca de uma formação necessária para uma prática renovadora. Cabe ao professor dar início a uma reforma do pensamento, apesar das instituições tentarem bloquear suas iniciativas, enfim, persistência e dedicação, quando se acredita nas próprias idéias.
\end{abstract}

Foi possível notar manifestações como essas em diversas ocasiões, indicando que essa visão da profissão pouco se modificou ao longo do processo. Não foi 


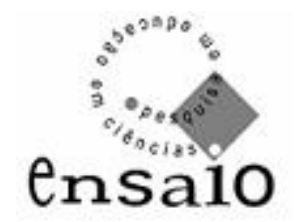

Vol. 10 no. 1 jun. 2008

percebido valorização da organização coletiva ou envolvimento político na busca de soluções para as dificuldades encontradas. Ressalte-se que uma das críticas freqüentemente elaboradas à concepção de professor reflexivo, sobre a qual se assenta o referido curso, é justamente o caráter individual da reflexão, o que pode ter colaborado no pouco avanço que se observou com relação a esta questão.

Por outro lado, a pesquisa, um dos fundamentos deste modelo formativo, passou a ser valorizada pelos docentes, como se percebeu em algumas manifestações obtidas no último questionário, tomadas como exemplos: “[com a graduação] deixa-se de ser um mero professor repetidor de fórmulas e conteúdos programáticos, para ser um pesquisador e estimulador da pesquisa dos alunos”; “as dificuldades aparecem, não só para os iniciantes, mas também para os veteranos, o importante é termos um espírito investigador sobre as questões apresentadas”. O fato de terem realizado uma pesquisa para elaboração do TCC pode ter contribuído para esta valorização. Reis (2007), por exemplo, notou a falta que faz um processo investigativo na formação acadêmica de docentes em serviço.

Embora, explicitassem, desde o início, a importância do curso para seu aperfeiçoamento profissional, no começo fizeram alusão também a outros fatores que os motivaram a participar do mesmo (imposição legal e melhoria salarial, por exemplo). Com o decorrer do processo, tais aspectos foram cada vez menos lembrados, sendo a formação contínua considerada como forma de realização pessoal e profissional, conforme os seguintes trechos extraídos do questionário aplicado no último semestre: “o curso de graduação (...) permite (...) a conscientização da necessidade de uma formação continuada”; “dá o desejo de sair para uma pósgraduação em busca de respostas para nossas incertezas, incertezas que sempre irão existir, se o indivíduo estiver sendo colocado à prova”.

Em relação às concepções sobre sua formação, notou-se que inicialmente estas eram fundamentadas predominantemente na racionalidade técnica, como pode ser observado fala de um dos docentes: "é como se a gente ainda tivesse esperando além do conhecimento, conhecer meios para transmitir esse conhecimento". No questionário aplicado ao final do curso, houve algumas manifestações que podem indicar certa mudança nesse aspecto, como, por exemplo: “a graduação é contagiante, fica o desejo de querer saber mais, o desejo pela pesquisa, o interesse em reformular, mudar, criar conceitos novos, descobrir novas fontes de conhecimento”. 


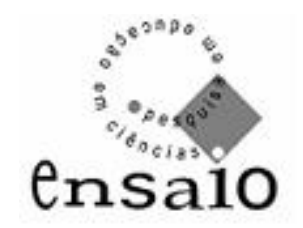

Vol. 10 no. 1 jun. 2008

No entanto, embora o projeto explicitasse que o profissional a ser formado fosse "crítico-reflexivo" e que utilizasse "os elementos de sua prática como fonte de reflexão e busca de soluções, alimentado, assim, continuamente a produção de novos conhecimentos” (UESB, 2003), este objetivo não foi plenamente alcançado, pois, em diversos aspectos, continuou presente a idéia de professor como mero executor no processo de ensino, fortemente dependente do livro didático (CALDAS, 2006). Aparentemente as oportunidades de reflexão sobre suas concepções de ensino e aprendizagem e sobre sua prática não foram suficientes para abalar de maneira decisiva as crenças epistemológicas de todos os participantes.

Os docentes tinham expectativa de que o curso proporcionasse fórmulas de atuação em sala de aula, conforme se constata na fala de um dos entrevistados: "o que a gente esperava era que a gente pudesse aplicar a vivência daqui lá nas escolas, na sala de aula”. Esta é uma situação bastante comum em formação em serviço (CHAVES, 2000; FREITAS e VILLANI, 2002; TRIVELATO, 2003;). Para Nóvoa (1998), a proposta de racionalização do ensino separa o trabalho de concepções das tarefas de sua realização, assim, “os professores são vistos como técnicos cuja tarefa consiste, essencialmente, na aplicação rigorosa de idéias e procedimentos elaborados por outros grupos profissionais” (p. 27). Nesse sentido, os docentes valorizaram as técnicas que puderam ser utilizadas em suas aulas: "O trabalho de invertebrados que nós fizemos com o professor [na universidade], e eu fiz com os meus alunos, eles até vibraram. Então a gente espera ter mais isso, atividades que nos levam a trabalhar com os nossos alunos, mais direcionadas a prática”; “a questão de trabalhar seminários, hoje nós temos assim mais liberdade pra trabalhar com os nossos alunos, foram desenvolvidas técnicas que nos levam também a estar trabalhando com os nossos alunos”.

Os conteúdos relativos ao campo pedagógico, que tivessem uma dimensão mais ampla, eram normalmente tidos como interessantes, mas inaplicáveis, como se explicou um dos entrevistados: "principalmente quando se trata da didática, da psicologia, principalmente quando cita aqueles teóricos, a gente sabe muito bem fazer a comparação e dizer que não funciona desse jeito”.

Esse tipo de manifestação é comum em cursos de formação acadêmica em serviço, conforme já haviam apontado Santos (2003) e Reis (2007). Percebe-se, portanto, um distanciamento entre os conhecimentos acadêmicos e a prática docente. 


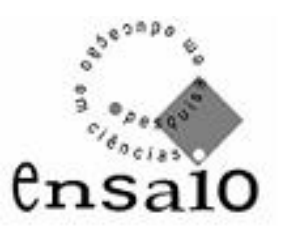

Vol. 10 no. 1 jun. 2008

Para Tardif (2000), essa distância pode assumir diversas formas: da rejeição aos saberes teóricos à sua seleção, adaptação e transformação a fim de incorporá-los à prática:

(...) a prática nunca é um espaço de aplicação dos conhecimentos universitários. Ela é, na melhor das hipóteses, um processo de filtração que os dilui e os transforma em função das exigências de trabalho; ela é, na pior das hipóteses, um murro contra o qual se vêm jogar e morrer conhecimentos universitários considerados inúteis, sem relação com a realidade do trabalho docente diário nem com os contextos concretos de exercício da função docente (TARDIF, 2000 p. 12).

Assim, observou-se que os professores ingressaram no curso com expectativas de aprender técnicas e conteúdos que pudessem ajudá-los a melhorar sua prática docente, a qual não estava em questão. Quando começaram a notar divergências entre a mesma e o conhecimento acadêmico, tenderam a desconsiderá-lo, justificando esse movimento pela não-adequação de tais conhecimentos nos contextos concretos de suas salas de aula. Muitos foram gradativamente tematizando sua prática, sendo que, ao final do curso, notaram-se expressões da importância do conhecimento acadêmico na análise da prática, como se percebe em alguns trechos extraídos do questionário aplicado no último semestre: "iniciar o curso depois de estar atuando é gratificante, pois, a todo o momento estamos comparando a nossa prática, revendo as nossas falhas, na busca constante de uma melhora”; “curso de graduação, para quem já tem bastante experiência em ensinar, destaca-se pela possibilidade de confrontar teoria e prática, o que permite a revisão de atitudes (...)”; “os que agora cursam uma faculdade e já são experientes, posicionam-se como expectadores de suas próprias ações, questionando como a faculdade interfere em sua prática tão cristalizada.”

Nesse momento também, um dos docentes expressou seus questionamentos a respeito do saber da experiência:

Descobri também que a experiência acumulada pode não passar de ilusão, às vezes confiamos muito nessa tal experiência e deixamos de pesquisar com mais vigor (...). Antes pensava que a experiência ultrapassava meus limites, hoje vejo que preciso questionar mais, duvidar, pesquisar, debater com garra.

Outro movimento observado no decorrer do curso foi com relação a uma concepção transmissivista de aprendizagem para uma visão mais complexa, como 


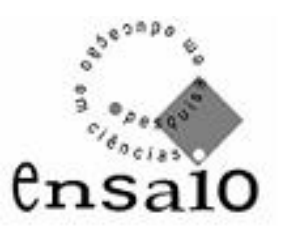

Vol. 10 no. 1 jun. 2008

algo pessoal, do qual o aprendiz participa ativamente. Alguns dos participantes citaram a perspectiva histórica deste movimento, como por exemplo:

Há tempos atrás o ensino era voltado diretamente para o professor que seria o narrador, o sabedor de tudo, o transmissor de conhecimentos, o aluno nada mais era que um espectador sem direito a argumentar, discutir, debater. Com o passar do tempo, ou melhor, hoje, este tabu já não existe e o aluno tem livre direito de debater e argumentar.

O processo de ensino em nosso país ainda está em fase de transição, saindo do tradicionalismo, onde o professor era o centro do conhecimento, sabedor de tudo, para uma prática mais centrada no aluno, considerando-o em suas diversas dimensões, não mais como uma tabula rasa, mas como alguém que já traz consigo uma diversidade de conhecimentos que devem ser aproveitados em sala de aula.

Outros mencionam seu caráter pessoal, como, por exemplo: "hoje vejo a coisas com outro olhar e descobri também que decorar não significa conhecimento, saber, e sim, elaborar meus próprios conceitos”.

Novamente perceberam-se aqui retornos e contradições. Por exemplo, em resposta ao questionário aplicado ao final do curso, uma professora admite: “o aluno é a peça mais importante deste processo e o nosso papel como facilitador é imprescindível”, no entanto, no mesmo texto, mais adiante considera que o professor deve buscar aperfeiçoamento constante, pois "precisamos aprender e repassar para nossos alunos”.

Outros demonstraram, em suas falas, não ter modificado sua concepção de conhecimento como algo pronto, que pode ser transferido integralmente de um indivíduo para outro: "para um professor (...) resta passar para os alunos o que aprendeu com tranqüilidade, porque não há motivos para preocupação, e sim, alegria e satisfação em saber que agora se pode ensinar com mais qualidade”.

No entanto, considerou-se, que a ênfase dada às atividades em grupo e a busca de uma maior participação dos alunos observada em suas práticas, sob certos aspectos, refletem a valorização da dimensão social da aprendizagem. Também se pode compreender que as estratégias didáticas dinâmicas e diversificadas, bastante utilizadas pelos docentes em seus projetos de inovação aplicados em sala de aula, na disciplina Estágio III, são tributárias do entendimento do caráter pessoal e complexo da construção do conhecimento. 


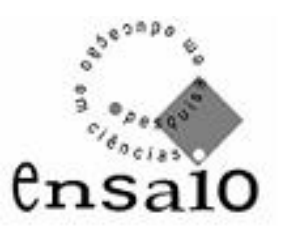

Vol. 10 no. 1 jun. 2008

Ou seja, o curso causou impacto sobre os docentes e suas práticas, embora nem sempre no sentido almejado em seu projeto. Ou como disse uma das cursistas: "[com a graduação] adquiri subsídios para melhorar, corrigir ou permanecer com a minha forma de ensinar”.

\section{7 - Considerações finais}

Os participantes manifestaram-se satisfeitos com o desenvolvimento do curso e alegaram que conseguiam fazer relações entre os conteúdos estudados e sua prática cotidiana. Apreciaram as experiências de aprendizado, especialmente aquelas mais dinâmicas e que puderam ser transpostas para suas salas de aula. Valorizaram a oportunidade de aprimoramento trazida pelo curso e exprimiram a intenção de continuar estudando. Portanto, é necessário o estabelecimento de políticas que garantam a continuidade do processo formativo, as quais devem estar vinculadas à valorização da escola e de seus profissionais.

Tomando-se como referência os fundamentos teóricos que embasaram o curso, notou-se que o grupo não manteve um movimento linear, mas apresentou avanços, resistências e contradições, no decorrer do processo. Com isso, a pretensão de formar professores reflexivos, autônomos, não foi plenamente alcançada, visto que, sob certos aspectos, os docentes continuaram dependentes de uma fonte externa capaz de lhes oferecer conhecimento pronto. Ou seja, muito embora o curso tenha se embasado em um modelo formativo subsidiário da racionalidade prática, continuou presente, entre seus participantes, uma concepção de formação docente amparada na racionalidade técnica.

\section{Referências Bibliográficas}

BAHIA. Secretaria da Educação do Estado da Bahia. Instituto Anísio Teixeira. Programa de Formação de Professores: modalidade presencial. Salvador: SEC/IAT, 2003 (mimeo).

Secretaria da Educação do Estado da Bahia. Estatísticas. Disponível em: <www.sec.ba.gov.br/estatística/indicadores.htm> Acessado em: 20 jun. 2005.

Secretaria da Educação do Estado da Bahia Instituto Anísio Teixeira.

Formação de Professores: inicial Disponível em <http://www.bahia.ba.gov.br/ saeb/perfil99/iat_fin.htm> Acessado em 15 jun. 2006. 


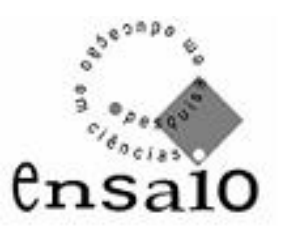

Vol. 10 no. 1 jun. 2008

BOGDAN R.C., BIKLEN, S.K. Investigação qualitativa em educação. Porto: Porto Editora, 1994.

BRZEZINSKI, I. A formação e a carreira de profissionais da educação na LDBEN 9.394/96: possibilidades e perplexidades. In: BRZEZINSKI, I (org.) LDBEN interpretada: diversos olhares se entrecruzam. 9a ed. São Paulo: Cortez, 2005 (147168).

CALDAS, S.N. O enfoque dado à caatinga nas aulas de Ciências. Curso de Especialização em Ecologia. Monografia (especialização). Universidade Estadual do Sudoeste da Bahia: Jequié, 2006.

CAMPOS, L.M.L., DINIZ, R.E.S. A prática como fonte de aprendizagem e o saber da experiência: o que dizem os professores de ciências e biologia. Investigações Ensino de Ciências. V.6, n.1, março de 2001. Disponível em $<$ http://www.if.ufrgs.br/public/ensino/revista.htm> Acessado em 20/06/2004.

CHAVES, S.N. A construção coletiva de uma prática de formação de professores de ciências: tensões entre o pensar e o agir. (tese de doutorado). Faculdade de Educação. Universidade Estadual de Campinas, 2000.

CHAPANI, D.T. RAZERA, J.C.C.; SOUZA FILHO, H.R, HORA; W.R.. Curso de licenciatura em ciências biológicas para professores não graduados: mudanças e influências sobre a prática pedagógica na percepção de seus participantes. In: ENCONTRO NACIONAL DIDÁTICA E PRÁTICA DE ENSINO (13), Atas ... Recife: UFPE, 2006a. (CD-Rom)

CONTRERAS. A autonomia do professor. São Paulo: Cortez, 2002

DINIZ-PEREIRA. J.E.As licenciaturas e as novas políticas educacionais para a formação docente. Educação e Sociedade, ano XX, n. 68, (109-125). Dezembro de 1999.

A pesquisa dos educadores como estratégia para a construção de modelos críticos de formação docente. In: DINIZ-PEREIRA, J.E.; ZEICHNER, K.M. (orgs.) A pesquisa na formação e no trabalho docente. Belo Horizonte: Autêntica, 2002.

DUARTE, N. Conhecimento tácito e conhecimento escolar na formação do professor (por que Donald Schön não entendeu Luria). Educ. Soc. V.24, n.83. (p.601-625), ag. 2003. Disponível em <http://www.scielo.br/pdf/es/v24n83/a15v2483.pdf> acessado em 02/09/2006

FLICK, U. Uma introdução à pesquisa qualitativa. 2. ed. Porto Alegre: Bookman, 2004

FREITAS, H.C.L. Certificação docente e formação do educador: regulação e desprofissionalização. Educ. Soc., vol. 24, n.85 (1095-1124), dezembro 2003.

FREITAS, D., VILLANI, A. Formação de professores de ciências: um desafio sem limites. Investigações Ensino de Ciências. Vol. 7, N. 3, dezembro de 2002. Disponível <http://www.if.ufrgs.br/public/ensino/revista.htm> Acessado em 20/06/2004

GHEDIN, E. Professor reflexivo: da alienação da técnica à autonomia da crítica. In: PIMENTA, S.G.; GHEDIN, E. (orgs.) Professor reflexivo no Brasil: gênese e crítica de um conceito. $3^{\mathrm{a}}$ ed. São Paulo: Cortez, 2005. (129-150)

MARCELO, C. Pesquisa sobre formação de professores: o conhecimento sobre aprender a ensinar. Revista Brasileira de Educação. v.9 (51-75) set/out/nov/dez, 1998.

MONTEIRO, A.M.F.C. Professores: entre saberes e práticas. Educação e Sociedade, ano XXII, n. 74 (121-142), abril, 2001. 


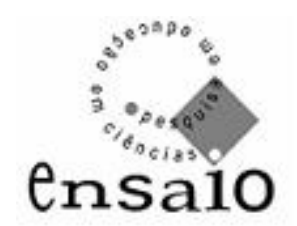

Vol. 10 no. 1 jun. 2008

NÓVOA, A. . Relação escola-sociedade: novas respostas para um velho problema. In: SERBINO, R.V. et al.(orgs). Formação de professores. São Paulo: Editora Unesp, 1998 (Seminários e debates)

PIMENTA, S.G. Professor reflexivo: construindo uma crítica. In: PIMENTA, S.G.; GHEDIN, E. (orgs.) Professor reflexivo no Brasil: gênese e crítica de um conceito. $3^{\mathrm{a}}$ ed. São Paulo: Cortez, 2005. (17-53)

RAMALHO, B.L.; NUÑEZ, I.B.; GAUTHIER, C. Formar o professor, profissionalizar o ensino: perspectivas e desafios. Porto Alegre: Sulina, 2004

REIS, M.E.T. Formação de professores leigos em exercício: um estudo sobre os saberes e práticas docentes em geometria. Universidade Estadual de Campinas. Faculdade de Educação. Dissertação (mestrado). Campinas: UNICAMP, 2007.

SANTOS, J.R.A. A mediação entre saberes na formação docente em exercício na região do Pico do Papagaio-TO. Universidade Estadual de Campinas. Faculdade de Educação. Dissertação (mestrado). Campinas: UNICAMP, 2003.

SANTOS, L.H;.CHAPANI, D.T. A prática de docentes universitários que atuam em curso de formação de professores em serviço. In: SIMPÓSIO SUL-BRASILEIRO DE ENSINO DE CIÊNCIAS. Atas....Blumenau: Universidade Regional de Blumenau, 2006.

SCHÖN, D. Formar professores como profissionais reflexivos. In: NÓVOA, A. (coord.) Os professores e sua formação. Lisboa: Don Quixote, 1995 (79-92).

UESB. Projeto do curso de licenciatura em ciências biológicas. Programa de formação de professores: modalidade presencial - $1^{\circ}$ etapa. Universidade Estadual do Sudoeste da Bahia - Departamento de Ciências Biológicas. Jequié: DCB, 2003.

TARDIF, M. Saberes profissionais dos professores e conhecimentos universitários: elementos para uma epistemologia da prática profissional dos professores e suas conseqüências em relação à formação para o magistério. Revista Brasileira de Educação. n. 13 (5-24). Jan, fev, mar, abr, 2000.

TRIVELATO, S. L. F. Um programa de ciências para educação continuada. In: CARVALHO, A.M.P. (coord.). Formação continuada de professores: uma releitura das áreas de conteúdo. São Paulo: Pioneira Thompson Learning, 2003. (63-86).

DATA DE RECEBIMENTO: 21/04/2007

DATA DE APROVAÇÃO: 02/10/2007

DATA DE VERSÃO FINAL: 04/11/2007 